\title{
AUDITORIUM SENI DI KOTA TUA JAKARTA
}

\author{
Steven Liputra ${ }^{1)}$ \\ 1) Program Studi S1 Arsitektur, Fakultas Teknik,Universitas Tarumanagara, liputrasteven77@gmail.com
}

\begin{abstract}
Abstrak
Kota tua merupakan sebuah wilayah kecil di Jakarta, Indonesia yang memiliki nilai sejarah yang tinggi karena menjadi pusat perdagangan benua asia karena lokasinya yang strategis dan sumber daya alam yang melimpah. Dan saat ini kawasan yang disebut Kota Tua sekaligus menjadi salah satu kawasan penting yang memiliki nilai sehingga bangunan-bangunan yang ada disana akan dipertahankan sebagai harta negara. Dan saat ini kawasan kota tua beralih fungsi menjadi kawasan yang memberikan pengetahuan sejarah dengan banyaknya bangunan museum, galeri, dan beberapa fungsi lainnya yang berhubungan dengan sejarah yang ada disana. Namun seiring berjalannya waktu, tidak adanya perkembangan program yang ada pada kawasan Kota Tua membuat para wisatawan mulai bosan dengan yang sudah ada saat ini. Dan beberapa mulai meninggalkannya. Berangkat dari permasalahan ini maka dibuat program baru yang diharapkan bisa mengubah Kota Tua menjadi kawasan yang memiliki program baru yang akan menarik wisatawan. Program proyek diharapkan bisa memberikan dampak positif dalam membantu meningkatkan daya tarik masyarakat baik di area kawasan maupun luar kawasan.
\end{abstract}

Kata kunci: permasalahan metropolis, program baru, sejarah

\begin{abstract}
Kota Tua is a small area in Jakarta, Indonesia which has a high historical value because it is the trading center of the Asian continent because of its strategic location and abundant natural resources. And now the area called Kota Tua is also one of the important areas that has value so that the buildings there will be preserved as state assets. And now Kota Tua is turning into an area that provides historical knowledge with many museum buildings, galleries, and several other functions related to history. But over time, the lack of development of existing programs in the Kota Tua area has made tourists become bored with what already exists today. And some began to leave. Departing from this problem, a new program was created which is expected to be able to turn Kota Tua into an area that has new programs that will attract tourists. The project program is expected to have a positive impact in helping to increase community appeal both in the area and outside the region.
\end{abstract}

Keywords: metropolis problem, new program, history

\section{PENDAHULUAN}

Kota tua yang dulunya dikenal sebagai Batavia Lama merupakan sebuah wilayah kecil di Jakarta, Indonesia. Wilayah yang terbilang khusus ini memiliki luas 1.3 kilometer persegi melintasi Jakarta Utara dan Jakarta Barat ( Pinangsia, Taman Sari dan Roa Malaka ). Kawasan ini memiliki sejarah yang bisa dibilang sangat bernilai karena menjadi pusat perdagangan benua asia karena lokasinya yang strategis dan sumber daya alam yang melimpah.

Dan saat ini kawasan yang disebut Kota Tua sekaligus menjadi salah satu kawasan penting yang memiliki nilai sejarah yang tinggi sehingga bangunan-bangunan yang ada disana akan dipertahankan sebagai harta negara. Dan saat ini kawasan kota tua beralih fungsi menjadi kawasan yang memberikan pengetahuan sejarah dengan banyaknya bangunan museum, galeri, dan beberapa fungsi lainnya yang berhubungan dengan sejarah yang ada disana.

Dari segi akses menuju kawasan pun tergolong mudah, baik yang berasal dari wilayah jakarta maupun yang diluar jakarta. Adanya akses kereta api yang bisa mencapai JABOTABEK membuat akses menuju lokasi akan sangat mudah dengan biaya yang murah. Bahkan jika 
dilihat dari jarak kawasan ke bandara pun tidak tergolong jauh karena adanya akses tol yang cukup dekat dengan kawasan sehingga mendukung terciptanya bangunan internasional dengan kemudahan tranportasi dan akomodasi. Terdapat bus dan taxi yang bisa memberikan kenyamanan untuk bisa sampai ke lokasi proyek.

\section{METODE PERANCANGAN}

Metode perancangan yang digunakan berupa pendekatan deduktif melalui literature dan dalam mencari dan mengumpulkan data. Selain melalui literature dan media elektronik, dilakukan juga survei lapangan terhadap beberapa bangunan pertunjukan yang sudah ada di jakarta serta melihat kondisi dan standar untuk bangunan pertunjukan yang masih layak digunakan. Metode selanjutnya adalah analisis kebutuhan ruang dan standar-standar ukuran untuk besaran auditorium melalui media elektronik maupun literatur, dan terakhir adalah fasade yang harus dipadukan dengan bangunan sekitarnya mengingat ini merupakan kawasan bersejarah.

\section{DISKUSI DAN HASIL}

Konsep pada bangunan pertunjukan seni yang terletak di kawasan Kota Tua ini diambil dari studi bentuk bangunan sekitar yang memang memiliki nilai tinggi sejarah disana. Dan untuk bentuk fasade dicoba untuk memadukan hal-hal yang sudah ada (yang menjadi ciri khas kawasan) dengan hal-hal yang baru namun masih termasuk dalam kategori ciri khas bangunan sekitar seperti pola pengulangan, jendela kotak dan lain sebagainya. Selain itu untuk konsep ruang dalam bangunan dibuat dengan skala besar agar terlihat megah dan indah jika dilihat dari dekat.

Bentuk massa pada bangunan ini adalah persegi panjang dengan 2 massa bangunan dengan area tengah yang digunakan sebagai area berkumpul sekaligus yang menghubungkan kedua bangunan. Selain itu area tengah juga menjadi penghubung dengan plaza yang langsung menyambut pejalan kaki yang ingin masuk ke bangunan sehingga semua berpusat pada satu titik. Dengan semua program pendukung yang mengelilingi sekitar bangunan dibuat jalur entrance utama untuk mobil berada pada sisi yang terdekat dari jalan raya yaitu terletak di bangunan utama yang memiliki area lobby paling besar.

Proyek bangunan pertunjukan seni yang dibuat ini bertujuan menjadi wadah baik bagi para penampilnya maupun para penonton yang ingin menikmati fasilitas baru ini. Karena dari hasil data yang didapat masih kurangnya fasilitas pertunjukan yang memadai di Jakarta. Selain itu, bisa juga memajukan kawasan sekitar yang terbilang kawasan besejarah yang tinggi sehingga bisa dibilang sangat cocok untuk berada di kawasan ini. 


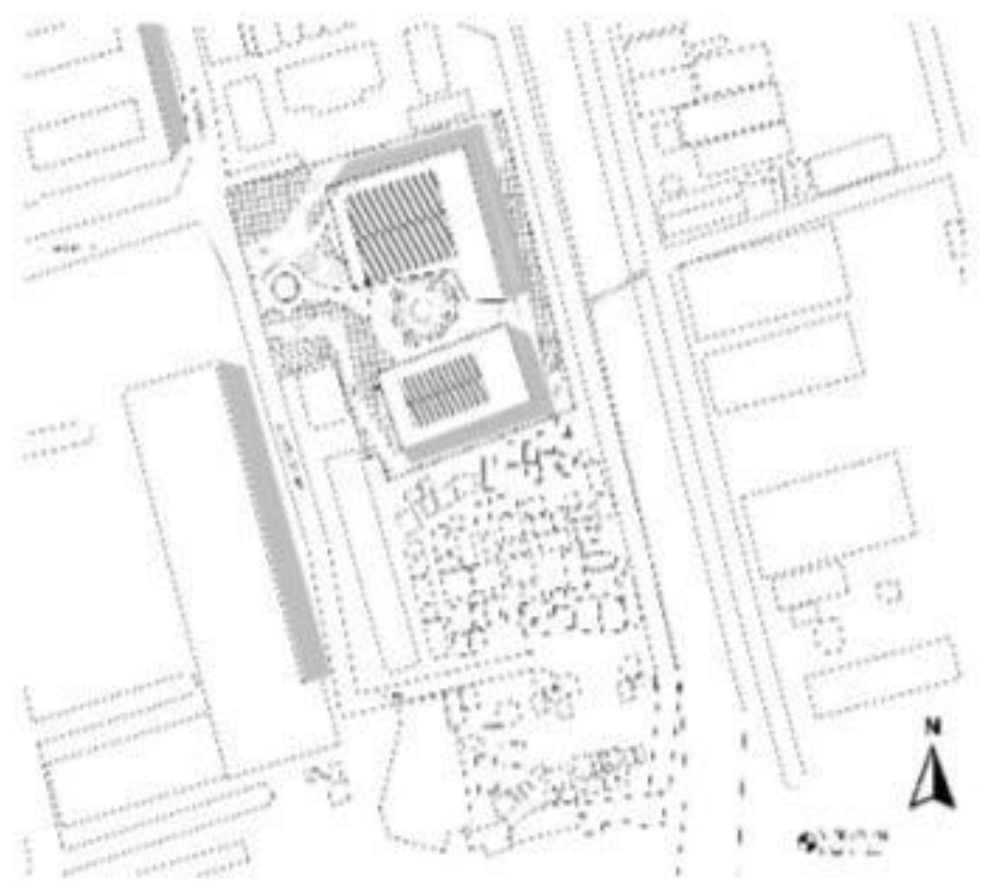

Gambar 2. Block Plan 


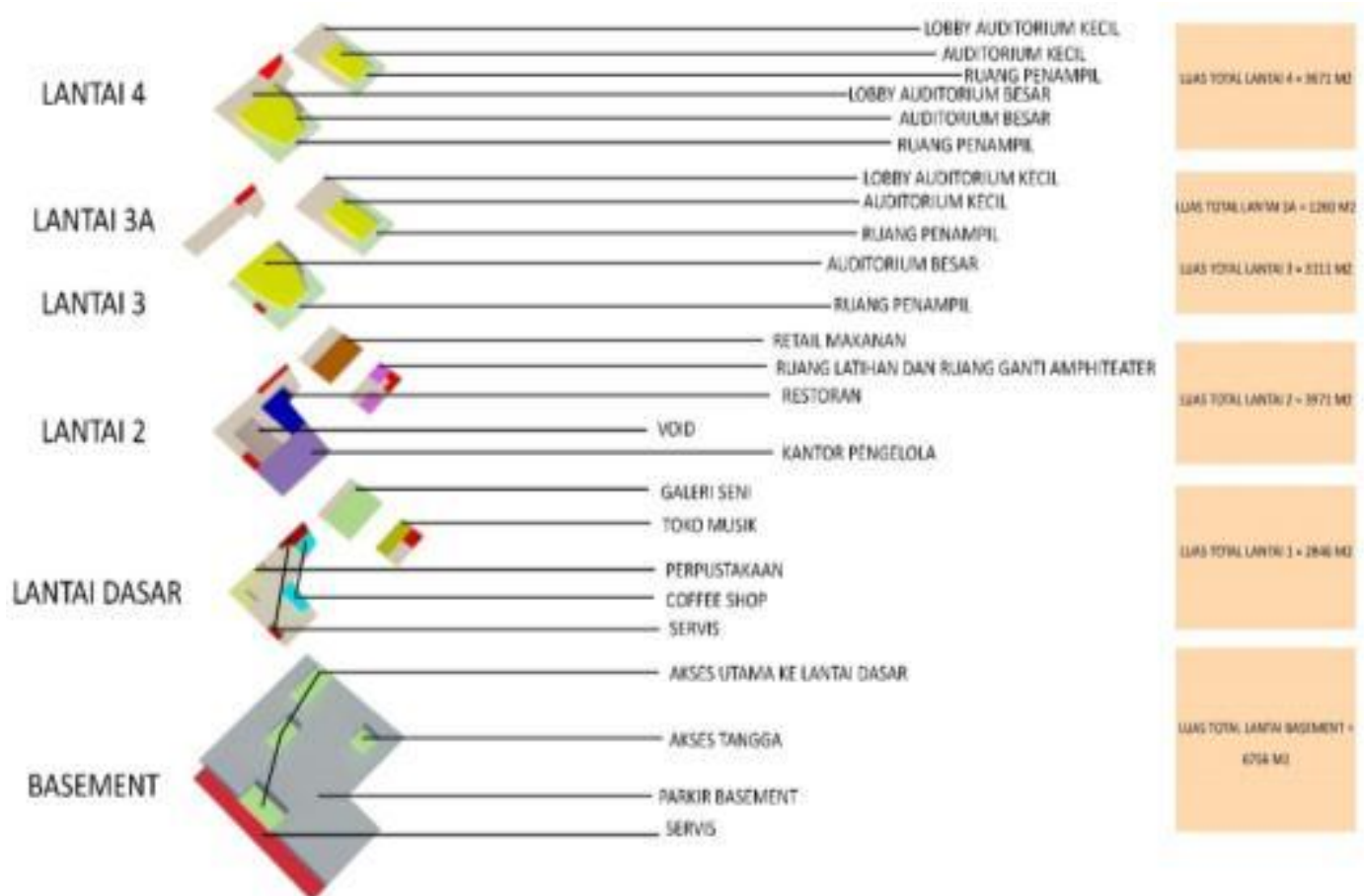

Gambar 3. Zoning ruang dan luas proyek tiap lantai

Selain sebagai wadah untuk pertunjukan seni, bisa juga dipakai sebagai sarana edukasi bagi para pemuda-pemuda di Jakarta. Selain itu ada juga fasilitaspenunjang lain seperti restoran, kafe, dan beberapa hal lain yang bisa didapatkan dari proyek ini Untuk posisi dari bangunan sendiri bisa dibilang sangat strategis mengingat lokasi proyek langsung berada dekat dengan jalan utama yang menuju ke arah jalan lada. Sehingga berpotensi bangunan akan dilihat oleh semua pengguna jalan pada area jalan kemukus.
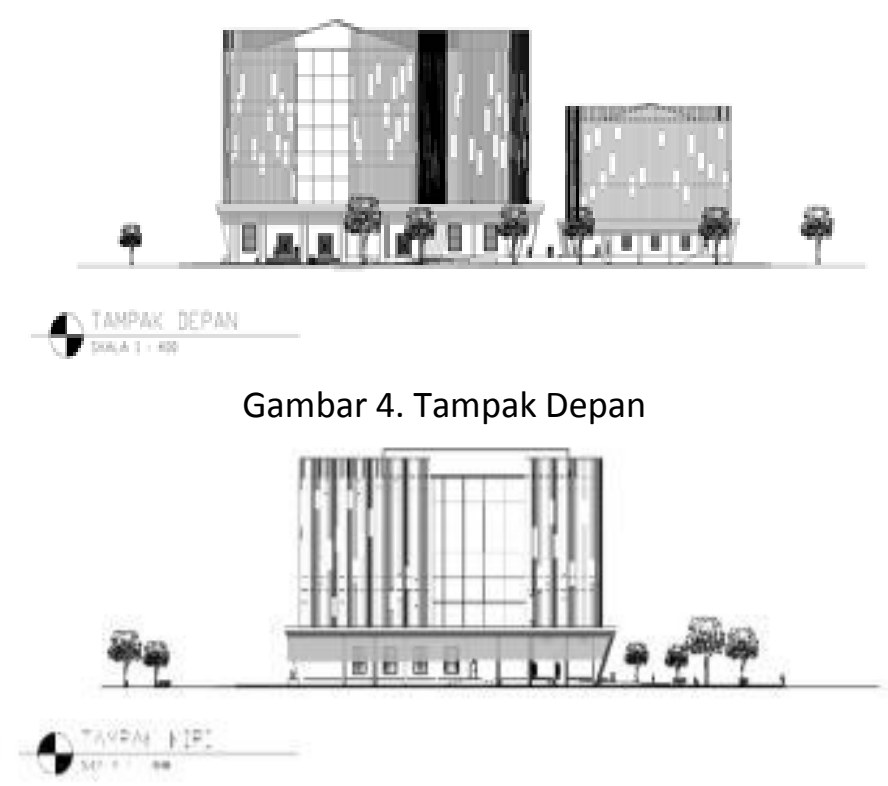

Gambar 5. Tampak Kiri 


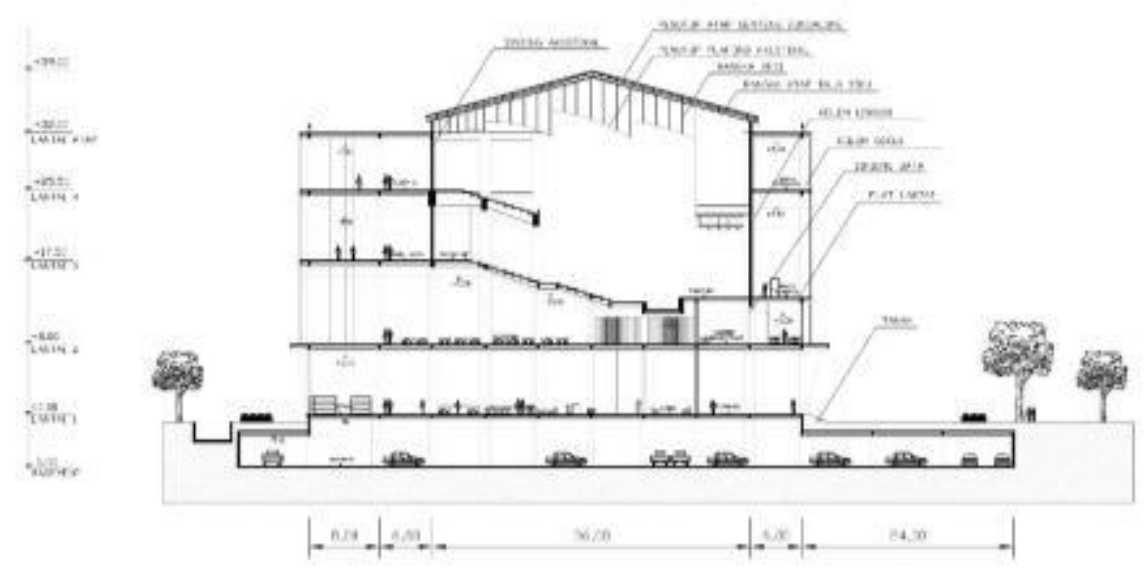

Q PITIINGAN $A-A$

Gambar 6. Potongan A-A
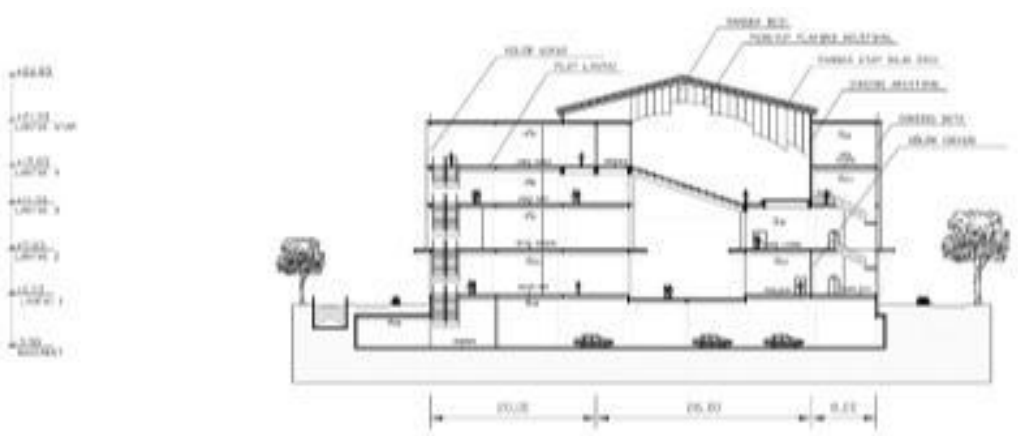

Gambar 7. Potongan B-B
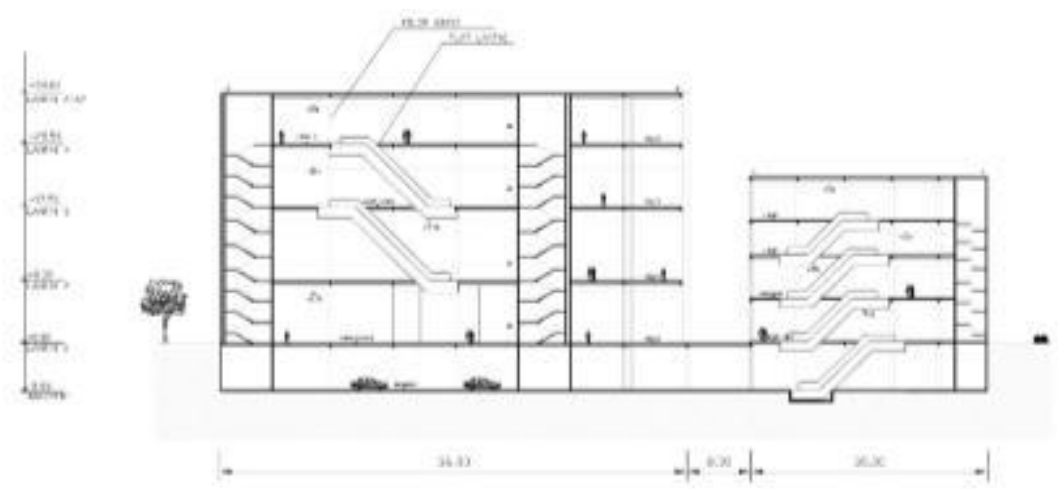

Gambar 8. Potongan C-C 


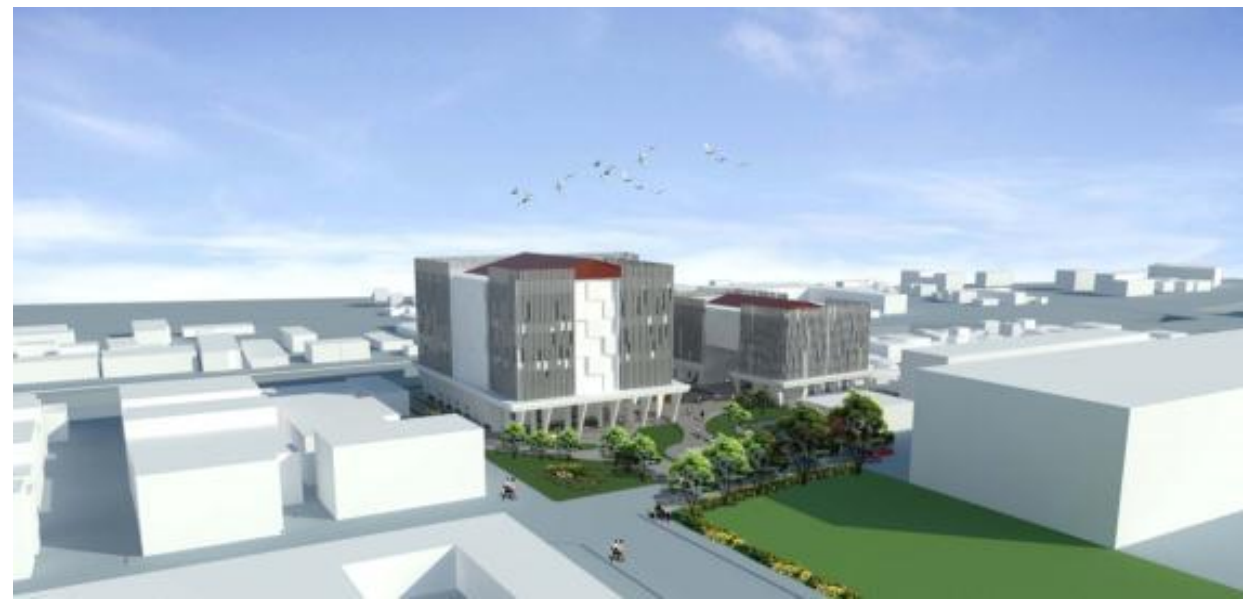

Gambar 9. Perspektif Eksterior

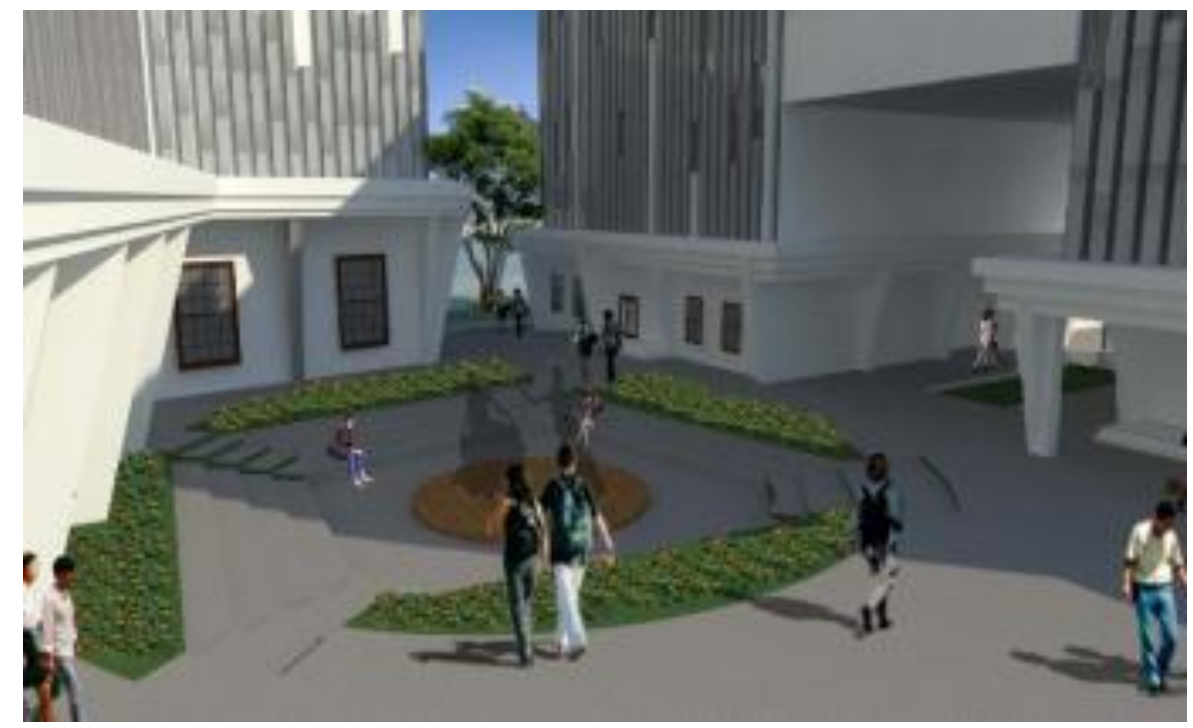

Gambar 10. Amphitheater

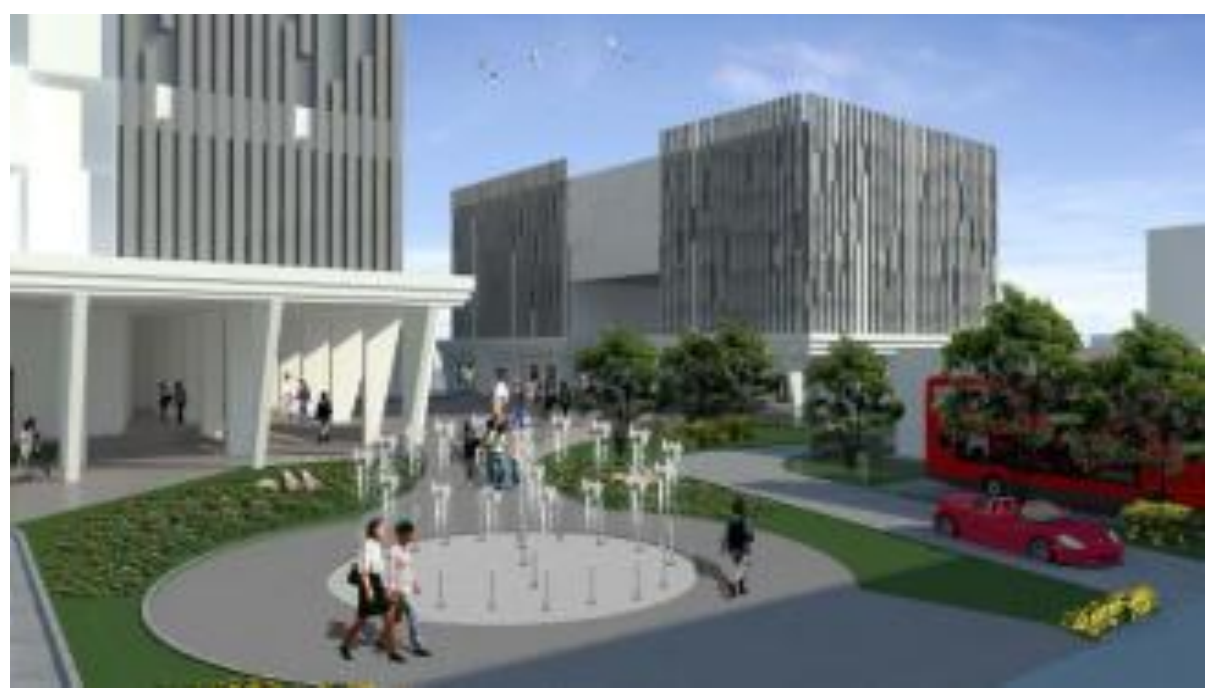

Gambar 11. Plaza 


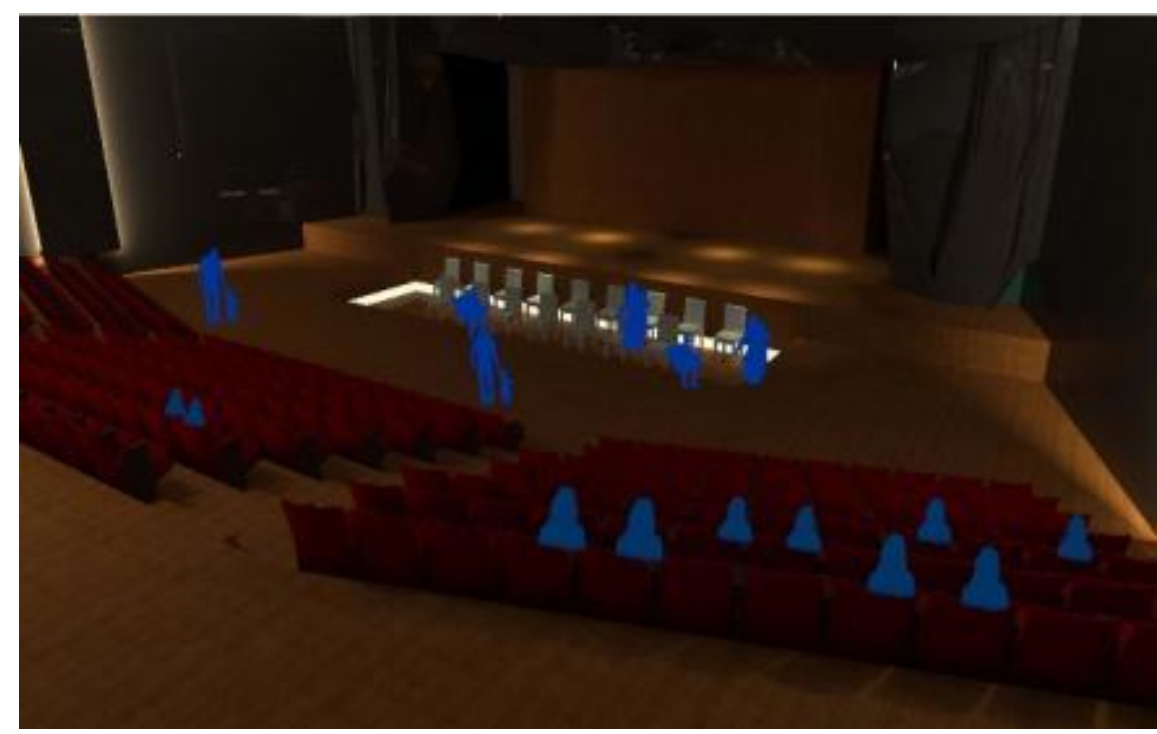

Gambar 12: Perspektif Interior auditorium besar

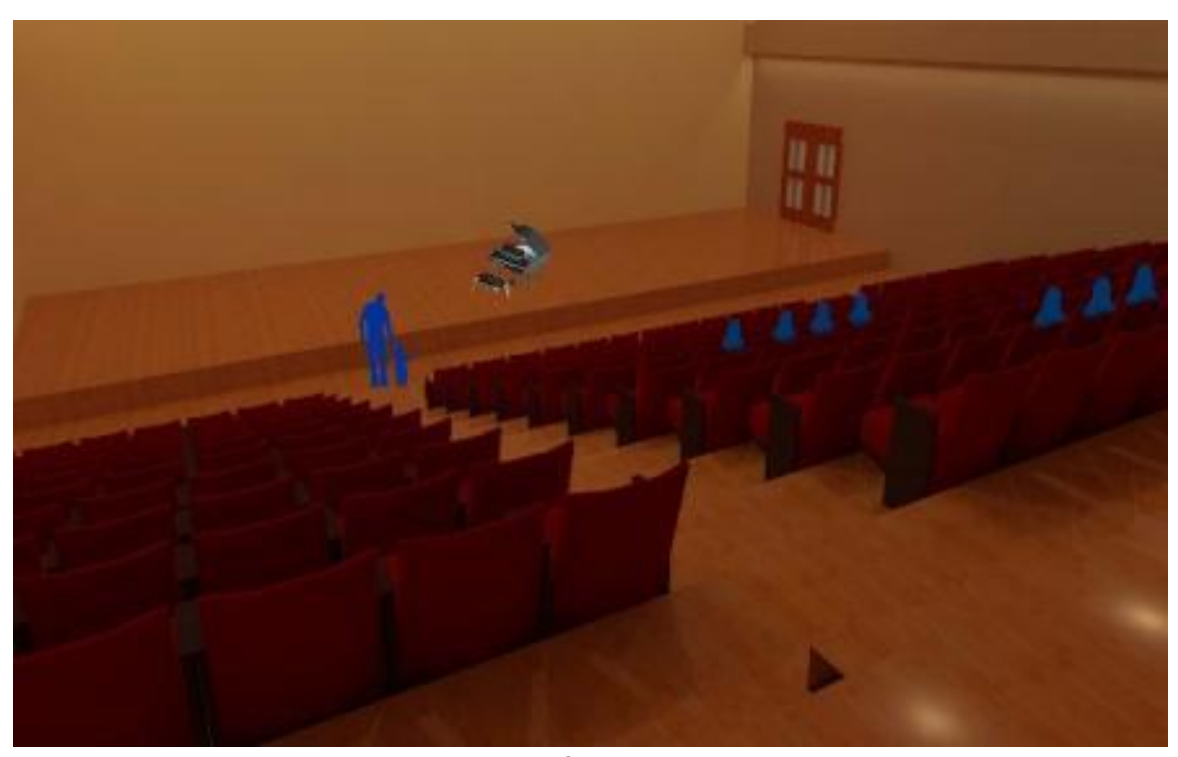

Gambar 13: Perspektif Interior auditorium kecil

\section{KESIMPULAN}

Bangunan auditorium seni pada proyek kali ini memiliki konsep yang terbilang baru pada kawasan Kota Tua, karena memadukan bentuk lama dengan bentuk yang baru sehingga tetap memiliki ciri khas dari kawasan tersebut. Pada proyek dibagi menjadi 2 massa yang masingmasing memiliki fungsi tertentu. Zoning pada bangunan ini juga dibuat berdasarkan analisa tapak dimana bagian entrance terletak di bagian yang menghadap jalan Lada Dalam karena sangat dekat dengan jalan raya kemukus. Dan terdapat plaza besar yang berada ditengahtengah proyek untuk akses para pejalan kaki yang menuju proyek.

\section{REFERENSI}

Davidson, R. and Maitland, R. (1997). Tourism Destinations. Lomdon: Hodder \& Stoughton Lynch, K. (1962). The Image of the City. MIT Press.

Hayllar, B.,T. Griffin, and Edwards D [eds]. (2008). City Spaces - Tourist Places: Urban Tourism

Precincts. Oxford: Elsevier

Selby M. (2004) Understanding Urban Tourism. IB Taurus 
Specht, Jan 2011. Architectural Tourism Building for Urban Travel Destination. Munich. Springer Gabler.

http://musicalprom.com/2015/11/05/mengapa-jakarta-perlu-pemerintah-untuk-mengelolapusat-kesenian/

https://www.pegipegi.com/travel/ini-alasan-kenapa-wisata-seni-indonesia-sepi-peminat/ https://www.cnnindonesia.com/hiburan/20151011105749-241-84245/darurat-gedung-

kesenian-khusus-pertunjukan-indonesia

http://www.komunitashistoria.com/agenda/event/67/

http://e-journal.uajy.ac.id/624/7/6TA12593.pdf

http://etheses.uin-malang.ac.id/1296/6/06560037_Bab_2.pdf

http://etheses.uin-malang.ac.id/1296/7/06560037_Bab_4.pdf

http://id.altaintegra.com/arsitektur-gedung-pertunjukan-seni-musik-opera-drama-tari

http://repository.upi.edu/20221/5/S_TB_1104148_Chapter2.pdf

Candela, The Shell Builder, Colin Faber Reinhold Publishing Corp, New York

Ishar, H.K; 1995, Pedoman Umum Merancang Bangunan, Gramedia Pustaka Utama, Jakarta

Joedicke, Jurgen, 1963, Shell Architecture, Reinhold Publishing Corporation, New York

Schodeck, Daniel L; 1980, Structure, USA Prantise Hall- Inc

Sutrisno, R; 1983,Bentuk Struktur Bangunan Dalam Arsitektur Modern, Gramedia, Jakarta

Salvadori, Mario, M. Levy,1986, Desain Struktur Dalam Arsitetektur (Terjemahan), Erlangga, Jakarta

http://www. greatbuildings.com

http://www.sydneyoperahouse.com 